\title{
Sentidos da escolha e da orientação profissional: um estudo com universitários ${ }^{1}$
}

\author{
Sense of choice and career guidance: \\ a study with university students
}

\author{
Telma Maranhão Gomes PINTO2 \\ Marisa Irene Siqueira CASTANHO ${ }^{3}$
}

\begin{abstract}
Resumo
O objetivo deste estudo foi apreender os sentidos da escolha e da orientação profissional, produzidos por universitários, com base nos fundamentos teórico-metodológicos da perspectiva sócio-histórica. Participaram da pesquisa 88 alunos de dois cursos de graduação de uma universidade pública, que haviam frequentado um Programa de Orientação Profissional entre 2003 e 2008. Os participantes responderam a um questionário, sendo suas respostas organizadas em tabelas para caracterização da clientela, situação no curso e participação no programa. Na segunda fase da pesquisa, foram selecionados 7 participantes para entrevista orientada pelos instrumentos Frases incompletas e Relatos Orais sobre a Escolha Profissional e Trajetória Acadêmica. O processo de análise dos sentidos deu-se pelo destaque das expressões subjetivas articuladas às condições contextuais e históricas dos sujeitos, chegando-se aos núcleos de significação. Os resultados indicaram, para o grupo estudado, que a Orientação Profissional foi contributiva e relevante para as escolhas acadêmicas e profissionais no percurso do Ensino Superior e para os projetos de futuro profissional.
\end{abstract}

Unitermos: Ensino superior. Estudantes universitários. Orientação profissional. Psicologia sócio-histórico. Sentidos.

\begin{abstract}
The aim is to apprehend senses of choice and vocational guidance, produced by university students. Participants were 88 students from two undergraduate courses of a public University, who had attended a Vocational Guidance Program between 2003 and 2008. The study was based on the theoretical and methodological foundations of social historical perspective. The answers to the questionnaire were organized in tables for characterization of the studied population, situation in the course and participation in the program. Seven participants were selected for interview guided by instruments "Incomplete Sentences" and "Oral Reports on the Professional Choice and Academic Career". The process of analysis of the senses was performed by the emphasis on the subjective expressions produced by the students, in conjunction with their contextual and historical conditions, to arrive at core meanings. The results indicate that for the studied group, the Professonal guidance Program was contributory and relevant to professional and academic choices on the way to higher education and to future career projects.
\end{abstract}

Uniterms: Higher education. College students. Occupational guidance. Sociohistoric psychology. Senses.

UVR

1 Artigo elaborado a partir da dissertação de T.M.G. PINTO, intitulada "Um estudo sobre os sentidos produzidos por universitários a partir da experiência em orientação profissional". Centro Universitário da Fundação Ensino para Osasco, 2010.

2 Universidade Federal Fluminense, Pró-Reitoria de Gestão de Pessoas, Programa de Orientação Vocacional/Profissional da Seção Psicossocial. Niterói, RJ, Brasil.

3 Centro Universitário da Fundação de Ensino de Osasco, Programa de Pós-Graduação em Psicologia Educacional. R. Franz Voegeli, 300, V. Yara, 06020-190, Osasco, SP, Brasil. Correspondência para/Correspondence to: M.I.S. CASTANHO. E-mail: <marisa.irene@unifieo.br>. 
Este artigo trata da relevância da Orientação Profissional (OP) para o aluno universitário, entendida como um campo da prática oferecida, nas últimas décadas, a jovens brasileiros com acesso a esse nível de ensino. $\bigcirc$ oferecimento da OP aos universitários tem-Ihes dado a oportunidade de vivenciar uma intervenção constituinte e determinante do processo de superação de dificuldades ligadas à dúvida sobre a escolha profissional, bem como da consolidação de perspectivas, na vivência das exigências da vida acadêmica no Ensino Superior.

A realidade social, em contínuas transformações, traz consequências a todos os seus segmentos, inclusive no mundo do trabalho. Segundo Marques (2007), em sua investigação no campo da OP, o avanço da tecnologia, a flexibilização do trabalho e a globalização da economia são alguns dos fatores a serem considerados no processo de escolha profissional e de permanência nos cursos de formação, assim como na constituição da subjetividade dos jovens estudantes universitários.

Desde o ingresso na graduação, a partir da escolha profissional até sua efetivação, há um caminho repleto de fatores que determinam o processo de formação do universitário até a conclusão de curso e a consolidação da profissão desejada. Essa demanda tem sido implementada e pesquisada em vários programas por profissionais da área, a exemplo de Marques (2007), Telerman (2004) e Valore (2005), que defendem o oferecimento de suporte específico para a reflexão sobre projetos futuros como atividade essencial para o desenvolvimento dos jovens como seres humanos. Dias (2009) contribui para o avanço teórico na questão do futuro profissional do universitário, por meio da compreensão dos sentidos do trabalho presentes na construção do projeto de vida de um grupo de formandos de universidade pública; Calejon (1995; 1996) e Portilho (1995) têm como ponto de partida das discussões o apoio a ser oferecido a graduandos, visando ao desenvolvimento de projetos acadêmicos e à integração na realidade universitária; Novaes (2003) discute as contradições existentes na construção da escolha profissional dos jovens e as determinações sociais; Zago (2006) trata da temática das condições de permanência do universitário no Ensino Superior; Dias e Soares (2009) abordam um trabalho de orientação profissional para estudantes universitários com o foco no Planejamento de Carreira.
Outros estudos, como o de Moura e Silveira (2002), defendem a intervenção em OP como um novo espaço de aprendizagem e de apropriação de elementos fundamentais para a consolidação do processo de autoconhecimento, desenvolvimento pessoal e conhecimento das profissões. Moura, Sampaio, Menezes e Rodrigues (2003) concluem que os alunos participantes de grupos de OP, numa universidade pública, alcançaram com esta vivência a melhoria no autoconhecimento e o conhecimento da realidade profissional, além da aprendizagem do processo de tomada de decisão.

No Brasil, no que diz respeito à prática em OP, para além de uma abordagem tradicional pautada pelos testes psicométricos, o principal referencial é o trabalho do psicólogo argentino Bohoslavsky (1977), cuja proposição de uma estratégia clínica sugere uma modalidade de OP em que o sujeito da escolha é visto como ativo. O autor considera que o sujeito, para definir sua escolha profissional, deve fazê-la sobretudo privilegiando a ação reflexiva, a partir de elementos de sua subjetividade.

Estudos atuais como o de Aguiar, Bock e Ozella (2009) e o de Alfredo (2006) têm defendido a prática em OP como um processo que favorece o pensamento e a ação de modo crítico e, assim, contribui para que o sujeito tenha a chance de se apropriar dos múltiplos determinantes de sua escolha e compreenda o processo que está vivenciando, simultaneamente, como singular e histórico-social.

A pesquisa ora apresentada guia-se pela finalidade de se produzir um desdobramento dos elementos essenciais do processo de análise de dados levantados junto a alunos universitários. Dessa forma, situa-se em continuidade aos trabalhos mais recentes orientados pela compreensão da escolha profissional como relacionada a múltiplas e determinantes forças, na relação dialética entre subjetivação e objetivação de uma dada realidade social. Nesse sentido, o objetivo desta pesquisa foi apreender os sentidos da escolha e da orientação profissional, produzidos por alunos de dois cursos de graduação de uma universidade pública, que haviam frequentado um Programa de Orientação Profissional entre 2003 e 2008.

O sentido, como categoria de análise, é sustentado pelos pressupostos teórico-metodológicos da Psicologia sócio-histórica de Vigotski (2001), reiterada por seguidores. Para Vigotski (1998), todo fenômeno 
psicológico deve ser analisado como resultante da articulação dialética entre indivíduo e sociedade, objetividade e subjetividade, mundo psicológico e mundo social, destacando-se a historicidade como fundamental nas análises que se propõem a superar as concepções fundamentadas no empirismo, no individualismo e na naturalização da psique humana. Vigotski (1998) manteve, em sua produção, o posicionamento crítico, voltando-se para a necessidade do entendimento da constituição do indivíduo como sujeito ativo na realidade social e no próprio desenvolvimento.

Vigotski (2001) parte do conceito de significado entendido como unidade entre o pensamento e a palavra, a qual não pode se decompor, pois na complexa teia de relação entre o pensamento e a linguagem, a palavra não é, isoladamente, um fenômeno da linguagem ou do pensamento. Aguiar, Liebesny, Marchesan e Sanchez (2009), com base em Vigotski, destacam que o que faz a mediação na relação entre pensamento e linguagem é o significado. A representação da realidade, no pensamento, é formada a partir da linguagem (produzida social e historicamente) e dos significados da fala; e a ação concreta e material dos homens, mediada pelos significados, dá origem à linguagem e constitui a consciência. Assim, o sentido resulta de um complexo fenômeno de constituição da consciência, discutido por Vigotski no final de sua obra:

... O sentido de uma palavra é a soma de todos os fatos psicológicos que ela desperta em nossa consciência. Assim, o sentido é sempre uma formação dinâmica, fluida, complexa, que tem várias zonas de estabilidade variada. O significado é apenas uma dessas zonas de sentido que a palavra adquire no contexto de algum discurso e, ademais, uma zona mais estável, uniforme e exata (Vigotski, 2001, p.465).

Segundo González Rey (2007), nesse momento Vigotski reconhece, pela primeira vez, o caráter organizador da psique, sendo que o sentido toma forma, e passa a não ser mais apresentado apenas como função, nem da linguagem nem do pensamento, mas se apresenta também na relação com a fala interior, como produção psicológica, como complexa articulação entre pensamento, linguagem, fala, personalidade e consciência, como sistema em movimento.

Para o autor, o sentido, como categoria, faz parte da constituição da subjetividade do sujeito, e permite romper com as dicotomias consciente/inconsciente, social/individual, cognitivo/afetivo, "pois o sentido se produz de forma simultânea na integração dessas dimensões" (González Rey, 2004, p.52).

No que diz respeito à apreensão dos sentidos, Aguiar e Ozella (2006) afirmam que pelas expressões do sujeito, como manifestação de sua subjetividade, é possível apreender indicadores das suas formas de ser e dos processos vividos por ele. Apreender os sentidos "não significa apreendermos uma resposta única, coerente, absolutamente definida, completa, mas expressões do sujeito muitas vezes contraditórias, parciais" (Aguiar \&Ozella, 2006, p.228).

A análise dos sentidos produzidos pelos universitários, com base nas premissas teórico-metodológicas apresentadas, tem como norteadoras as seguintes perguntas: quais os significados da OP para o aluno universitário? A OP poderia ser compreendida como um instrumento de mediação favorável ao processo de conscientização da escolha profissional e à integração do aluno ao curso? Quais os sentidos produzidos a partir dessa vivência?

O processo de análise implicou tomar o sujeito, sobretudo no que diz respeito a sua subjetividade, como constituído na dialética subjetividade-objetividade da realidade de escolha profissional e de vivência, em um Programa de OP desenvolvido em uma disciplina da grade curricular. A linguagem, como mediação da subjetividade, foi considerada instrumento valioso para a pesquisa, como materialização das significações atribuídas pelo sujeito da pesquisa, e dos sentidos produzidos por ele sobre a realidade pesquisada.

\section{Método}

Trazer os alunos que vivenciaram o processo de OP, como participantes da construção do conhecimento, favoreceu a aproximação compreensiva ao fenômeno estudado.

O Programa de OP de que trata este estudo tem efetivação prevista em disciplina obrigatória denominada Tutoria II, nos cursos de Química e Química Industrial, em uma universidade pública, e vem sendo realizado desde o $2^{\circ}$ semestre de 2003 . A disciplina é oferecida no segundo semestre dos cursos, em encon- 
tros com duração de 2 horas-aula, nas quatro primeiras semanas do período letivo, com a finalidade de favorecer a reavaliação da escolha do curso, da profissão e do percurso acadêmico, bem como o planejamento das futuras experiências profissionais. A proposta é teórico-vivencial e desenvolve-se em três unidades: I) Autoconhecimento, escolha profissional, formação acadêmico-profissional e planejamento de carreira; II) Informação profissional sobre as áreas de Química e Química Industrial e III) Projeto de vida/Planejamento de futuro profissional. No final, os alunos produzem sínteses conclusivas do processo realizado. Uma das coordenadoras é pesquisadora neste estudo.

O desenvolvimento da pesquisa foi motivado pela consideração da importância da reflexão acerca da prática.

Para tanto, foram contatados os 113 universitários que haviam participado do Programa, no período de 2003 a 2008, dos quais 88 responderam ao convite, sendo 50 do curso de Química e 38 do curso de Química Industrial. Dessa maneira, teve início a primeira fase, com o encaminhamento de um questionário, que se encontra no Anexo 1.

Todos os participantes assinaram o Termo de Consentimento Livre e Esclarecido antes de sua inclusão na amostra, tendo o projeto sido aprovado pelo Comitê de Ética em Pesquisa da universidade, de acordo com o Protocolo n 016/2009.

A segunda fase da pesquisa constituiu-se de entrevista orientada por dois instrumentos: Relato Oral Sobre a Escolha Profissional e a Trajetória Acadêmica e Frases Incompletas. O relato oral teve por base as narrativas do sujeito, consideradas como sua representação da realidade e, como, prenhes de significados e reinterpretações, de acordo com Cunha (1997). As Frases Incompletas basearam-se em procedimento sugerido por Bohoslavsky (1977) e reiterado por González Rey (2005) como instrumento apto a analisar a subjetividade do sujeito, que deve complementar as frases com a primeira ideia que the venha à mente. Para essa fase foram selecionados sete participantes, considerando-se tanto a quantidade de itens respondidos no questionário, quanto a qualidade das respostas dadas. Assim, primeiro foram descartados os questionários com excesso de respostas em branco ou respostas evasivas; em seguida, usou-se o critério de composição de uma amostragem que representasse os conteúdos oferecidos, resultando nos sete sujeitos selecionados.

O instrumento de Frases Incompletas utilizado compôs-se de 39 itens (Anexo 2). Ambos os instrumentos favoreceram o acesso aos conteúdos que levaram à apreensão dos sentidos produzidos pelos participantes sobre a escolha e a orientação profissional.

\section{Resultados}

\section{Análise a partir do questionário}

Na primeira etapa da pesquisa, as respostas ao questionário foram organizadas de maneira a caracterizar os 88 participantes que acataram o convite: sexo: 54 (61\%) participantes do sexo feminino e 34 (39\%) do masculino; faixa etária: 44 participantes (50\%) entre 20 e 22 anos, 36 (41\%) entre 23 e 25 anos, 7 (8\%) entre 26 e 28 anos; estado civil: 83 (94\%) solteiros, 3 (4\%) casados, 2 (2\%) outros; escolarização anterior ao curso de graduação: 56 (64\%) cursaram o Ensino Fundamental em rede privada, parcial ou totalmente, 32 (36\%), em rede pública; 62 (70\%) fizeram o Ensino Médio em rede privada e 23 (30\%) em rede pública.

Quanto à situação dos alunos no curso superior, no momento em que participaram do Programa de OP, apresenta-se uma síntese dos dados na Tabela 1.

O primeiro aspecto a ser ressaltado é que apenas 27,3\% dos alunos referiram dificuldades de desempenho acadêmico no curso; 9,1\%, dificuldades de identificação com o curso e de desempenho; e 9,1\%, ambas as dificuldades, a despeito de 80,0\% dos alunos estarem se submetendo a verificações suplementares e 51,0\% deles terem realizado cancelamento de disciplina. Outro dado significativo diz respeito ao fato de 54,5\% dos alunos afirmarem não ter dificuldades no desempenho acadêmico ou na identificação com o curso, o que contrasta com os 35,2\% deles que referiram dificuldades no acompanhamento das disciplinas, 13,6\% com dificuldades de aprendizagem e 6,8\% que afirmaram falta de adequação do curso a seus interesses pessoais. Por fim, chama a atenção o fato de 77,2\% afirmarem que foi a afinidade com o curso desde o Ensino Médio o principal fator motivador da escolha, o que não parece suficiente para sustentar um bom desempenho. 
Os dados referentes à participação dos alunos no Programa de OP na disciplina Tutoria II, implicações para a formação acadêmica e questões profissionais apresentam-se sintetizados na Tabela 2.

Sobre as implicações da OP na vida acadêmica e em questões da escolha, 73,3\% referiram favoreci- mento de maior empenho no curso; 43,7\% consideraram contribuição para a reflexão sobre possibilidades e perspectivas profissionais; $37,5 \%$ referiram confirmação da escolha profissional; 34,3\% ressaltaram o favorecimento do pensar sobre a escolha do curso e sobre as dificuldades relacionadas à formação profissional; $28,1 \%$

Tabela 1. Situação no curso no momento de participação dos alunos no Programa de Orientação Profissional - Curso de Química e Química Industrial - período 2003-2008, Universidade Federal Fluminense. Niterói (RJ).

\begin{tabular}{|c|c|c|c|c|}
\hline Situação no curso & Química (n) & Química Industrial (n) & Total (n) & Total (\%) \\
\hline \multicolumn{5}{|l|}{ 1) Eventos no percurso ao longo do curso } \\
\hline Participação em verificações suplementares & 39 & 31 & 70 & 80,0 \\
\hline Cancelamentos semestrais de disciplinas & 24 & 21 & 45 & 51,0 \\
\hline \multicolumn{5}{|l|}{ 2) Fator motivador para a escolha do curso } \\
\hline Afinidade com o curso desde a formação do Ensino Médio & 42 & 26 & 68 & 77,2 \\
\hline Adequação às habilidades pessoais & 17 & 5 & 22 & 25,0 \\
\hline Destaque da profissão no mercado de trabalho & 5 & 8 & 13 & 14,7 \\
\hline Contato com pessoas que já haviam realizado o curso & 8 & 3 & 11 & 12,5 \\
\hline Informação prévia resultante de processos de OP & 2 & 1 & 3 & 3,4 \\
\hline \multicolumn{5}{|l|}{ 3) Experiência prática e profissional } \\
\hline Estagiários/técnicos & 6 & 6 & 12 & 29,3 \\
\hline Professores & 13 & 2 & 15 & 36,5 \\
\hline Pesquisadores de Iniciação Científica & 8 & 2 & 10 & 24,4 \\
\hline Pesquisadores em empresas & 1 & 1 & 2 & 4,9 \\
\hline \multicolumn{5}{|l|}{ 4) Dificuldades do aluno com o curso } \\
\hline Sem dificuldades no desempenho acadêmico e na identificação com o curso & 29 & 19 & 48 & 54,5 \\
\hline Com dificuldades no desempenho acadêmico & 11 & 13 & 24 & 27,3 \\
\hline Com dificuldades na identificação com o curso & 5 & 3 & 8 & 9,1 \\
\hline Ambas as dificuldades & 5 & 3 & 8 & 9,1 \\
\hline \multicolumn{5}{|l|}{ 5) Especificidades das dificuldades } \\
\hline Acompanhamento das disciplinas & 17 & 14 & 31 & 35,2 \\
\hline Programação e organização do curso & 7 & 4 & 11 & 12,5 \\
\hline Dificuldades de aprendizagem & 3 & 9 & 12 & 13,6 \\
\hline Falta de adequação do curso aos interesses pessoais dos alunos & 3 & 3 & 6 & 6,8 \\
\hline
\end{tabular}

Tabela 2. Implicações da vivência na Orientação Profissinal na formação acadêmica e em questões profissionais - Curso de Química e Química Industrial - período 2003-2008, Universidade Federal Fluminense. Niterói, (RJ).

\begin{tabular}{|c|c|c|c|c|c|c|}
\hline \multirow{2}{*}{$\begin{array}{l}\text { Implicações da vivência em Orientação Profissional na formação acadêmica e } \\
\text { questões profissionais }\end{array}$} & \multicolumn{2}{|c|}{ Química } & \multicolumn{2}{|c|}{ Química industrial } & \multicolumn{2}{|c|}{ Total } \\
\hline & $\mathrm{n}$ & $\%$ & $\mathrm{n}$ & $\%$ & $\mathrm{n}$ & $\%$ \\
\hline Aumento do empenho no curso & 11 & 65,0 & 11 & 84,6 & 22 & 73,3 \\
\hline Reflexão sobre possibilidades e perspectivas profissionais & 6 & 26,0 & 8 & 88,9 & 14 & 43,7 \\
\hline Confirmação da escolha profissional & 7 & 30,4 & 5 & 55,5 & 12 & 37,5 \\
\hline $\begin{array}{l}\text { Favorecimento do pensar a escolha do curso e as dificuldades relacionadas à } \\
\text { formação profissional }\end{array}$ & 6 & 26,0 & 5 & 55,5 & 11 & 34,3 \\
\hline $\begin{array}{l}\text { Favorecimento de decisões a serem tomadas e de elaboração de projetos de } \\
\text { futuro }\end{array}$ & 3 & 13,4 & 6 & 66,6 & 9 & 28,1 \\
\hline Ajuda na superação de dificuldades & 4 & 17,3 & 3 & 33,3 & 7 & 21,8 \\
\hline Maior conscientização na profissionalização, a partir do curso universitário & 4 & 17,3 & 2 & 22,2 & 6 & 18,7 \\
\hline Retomada do que já havia vivenciado em percurso acadêmico & 3 & 13,4 & 1 & 11,1 & 4 & 12,5 \\
\hline
\end{tabular}


destacaram favorecimento de decisões quanto aos projetos profissionais futuros; $21,8 \%$ referiram ajuda na superação de dificuldades. Destaca-se que, comparativamente, os resultados são mais expressivos para os alunos de Química Industrial. Outras contribuições: conscientização da profissionalização a partir do curso universitário (18,7\%) e a possibilidade de retomar o que já havia vivenciado em percurso acadêmico (12,5\%). Os alunos que não reconheceram contribuições da OP alegaram a falta de soluções objetivas para as dificuldades relativas às disciplinas e negaram ter dúvidas quanto à escolha do curso.

\section{Análise a partir dos relatos orais sobre a escolha profissional e a trajetória acadêmica e das frases incompletas}

Das inúmeras leituras das falas e expressões dos sete participantes nesta fase da pesquisa, destacaram-se pré-indicadores constituídos de temas e caracterizados pela frequência, repetição ou reiteração, bem como pela ênfase, carga emocional comunicada, ambivalências ou contradições. Os seguintes conteúdos temáticos foram organizadores das falas e expressões dos sujeitos: 1) elementos histórico-sociais: constituintes das condições materiais de vida do sujeito; 2) o que o sujeito pensa sobre si mesmo e como pensa ser visto pelo outro; 3) afetos e sentimentos: expressões de necessidades, contradições, afeições, motivações, sentimentos frente a determinadas situações; 4) elementos constituintes do direcionamento da vida: valores morais e ideológicos, concepção de homem, família e sociedade, valor do conhecimento e do estudo, visão do aluno, do professor, da formação acadêmica e profissional, da universidade; 5) apropriação e objetivação do conhecimento: referências sobre diferentes formas de apropriação do conhecimento, quer as de senso comum, quer as resultantes de processos formais de estudo, quer as referidas como originárias da relação entre estudo acadêmico e prática profissional; 6) elementos sobre a vivência acadêmica: trajetória, sucessos, dificuldades cognitivas e movimentos de superação destas no percurso da vida acadêmica; 7) escolhas: de curso, profissão e outras escolhas que integram a formação acadêmica e profissional; 8) orientação profissional: referências ao vivenciada no curso; 9) trabalho/profissão: referências à experiência de estágios, pesquisa, atividades práticas na universidade e outras e 10) projeto de vida: perspectivas profissionais, acadêmicas e pessoais.

Os pré-indicadores foram aglutinados por complementaridade, similaridade ou contraposição, dando origem aos indicadores, de acordo com Aguiar e Ozella (2006). Por uma nova aglutinação dos indicadores pelo mesmo procedimento, chegou-se aos núcleos de significação reveladores do movimento contraditório manifestado no conjunto das expressões, ao mesmo tempo individuais e coletivas, subjetivas e objetivas, racionais e afetivas, que revelavam os modos de sentir, pensar e agir de cada um. O Anexo 3 ilustra esse movimento de organização e aglutinação, a partir das falas e expressões dos sujeitos em pré-indicadores, indicadores e núcleos de significação.

As falas e expressões constantes no Anexo 3 possibilitam compreender o processo de análise, pela contextualização temática e pela organização de pré-indicadores e indicadores, até chegar aos núcleos de significação.

Inicialmente, destaca-se a predominância de alguns pré-indicadores e indicadores que, de forma integrada, correspondem a uma concepção liberal de homem, visto como responsável por si mesmo, por sua vida pessoal e profissional, que pode tudo, desde que se empenhe e acredite em seu esforço pessoal. Em seu conjunto, esses indicadores levam à formação de dois núcleos de significação, o primeiro sintetizado pelas expressões Não pode desistir de nada!, Tem que correr atrás!, Tudo dá certo, se tiver nosso empenho! O segundo, coadunando com a visão liberal de homem e com as autocobranças que os sujeitos da pesquisa se fazem, sintetiza-se na significação Universitário responsável pela sua vida pessoal, acadêmica e profissional.

A despeito das inúmeras dificuldades decorrentes de condições adversas de moradia e situação financeira, entre outras, os participantes percebem suas dificuldades como individuais, reagindo com desânimo e vontade de parar a faculdade. Mas, diante da valorização dada ao estudo, ao conhecimento e à profissão como fontes de realização, sucesso e ascensão, acabam por supor que as dificuldades pertencem a um conjunto de problemas cuja solução está na superação e na persistência. 
As expressões dos sujeitos, fruto da objetivação de sua subjetividade, resultam dos valores e concepções que as constituem como determinantes histórico-sociais. No entanto, muitas vezes, os sujeitos (afetados por sentidos por eles mesmos produzidos) não têm consciência dos determinantes desse processo de produção, ignorando que sua produção afetivo-cognitiva é, também, histórico-social. Por isso, apresentam angústia e insegurança, apreendidas por indicadores referentes ao desânimo e ao estar só, com suas dificuldades.

Em sintonia com essa visão liberal de homem capaz por si só, outros indicadores mostram a importância dada ao estudo e à formação acadêmica como elementos constituintes do direcionamento da vida, dando-Ihes o significado de um caminho de sucesso, o conhecimento como ascensão intelectual e realização pessoal. Essa realização se entrelaça necessariamente à realização financeira, aglutinando um núcleo de significação: Estudo: realização pessoal x profissional, social e financeira.

Ainda a respeito do significado do estudo e da formação acadêmica, da aprendizagem profissional e da prática de estágio, a educação é predominantemente significada pelos participantes como uma via de alcance da ascensão e mobilidade social. O conjunto de indicadores que apontam essa direção de integração entre o significado do estudo, as demandas da formação e a prática profissional possibilitou constituir um núcleo de significação Condições para a apropriação do conhecimento como determinante do desempenho acadêmicoe da confirmação da escolha profissional.

Sobre a educação universitária, especificamente no que diz respeito ao estágio, os participantes produzem significações que indicam a importância desse exercício também como um investimento voltado para a qualificação profissional e a empregabilidade futura. Entretanto, a atenção da universidade para o estágio concretiza-se em estreitas oportunidades e, por isso, provoca nos participantes um estado subjetivo que mescla angústia e falta de perspectiva empregatícia. Talvez seja esse um dos fatores, para alguns alunos, que favoreçam a busca de uma nova graduação, geradora de maiores possibilidades de ingresso no mercado de trabalho.

As necessidades e motivos relativos ao mundo do trabalho, em confronto com as condições reais de formação profissional e a necessidade de enfrentamento de obstáculos, contribuem para a formação de uma condição contraditória e sofrida. Terminar o curso, com a expectativa de conquistar o diploma, conseguir a independência financeira e, ao mesmo tempo, a segurança em relação à escolha profissional feita, não se consolida em alguns casos ou aparece apenas como nuance de possibilidades, em outros. Nesse sentido, embora participantes já formados tenham relatado a certeza de ter adquirido uma boa base para o trabalho, também verbalizam insatisfação com as condições de salário e contratação, e evidenciam a necessidade de ampliar seus conhecimentos e investir na qualificação. Essas seriam condições fundamentais para manter suas perspectivas e alcançar as condições idealizadas de trabalho. Em todos esses casos, deixam transparecer a incerteza quanto ao futuro, sugerindo um núcleo de significação: projeto de futuro como contradição entre a certeza e a incerteza da escolha.

Contraditoriamente à visão liberal de homem, capaz por si só de dar conta da própria vida, simbolizada pelo ter que correr atrás, depreendeu-se a mediação de outros elementos orientadores para a vida, advindos de lastro ético-religioso: a realização, inclusive a profissional, estaria nas mãos de Deus. Nesse caso, a possível concretização dos planos pessoais e de realização profissional organizou-se em um núcleo de significação fundamentado em mandamentos religiosos: O futuro nas mãos de Deus.

Quanto à disciplina Tutoria II (vivência da OP), depreenderam-se tanto indicadores positivos de sua contribuição para ajudar o aluno a enfrentar dificuldades no curso, quanto, contrariamente, de sua inutilidade, por apenas confirmar a escolha feita. Assim, o núcleo OP como conscientização da real situação no curso contrapõe-se à significação da $O P$ como tardiamente reveladora daquilo que já se sabia.

No primeiro caso, uma aluna afirma que até o momento da vivência na OP, "não tinha caído a minha ficha, em relação a minha real situação no curso"(Sic). Assim, a denominação da OP como processo proveitoso com ênfase na ideia de que ela ajuda o aluno a ter uma visão de sua posição no curso. No seu caso, a desmotivação e a ideia de parar a universidade foram declinando, deixando lugar para o desdobramento de novas atividades acadêmicas, favorecedoras da apropriação do conhecimento acadêmico, em níveis satisfatórios. 
Isso Ihe possibilitou certificar-se da identificação com a área de trabalho escolhida e dar novo significado a sua escolha profissional.

No segundo caso, em consonância com o ideário dos participantes da pesquisa (predominância da concepção liberal de homem), destaca-se a ideia de terem feito a escolha certa e de que a OP só serviu para afirmar o que já se sabia. Para uma das participantes, a OP não mostrou um caminho novo, apenas a ajudou a ter certeza do que já sabia que queria fazer. Conforme diz: "eu já sabia que queria fazer Química, o processo de orientação só serviu pra me firmar mesmo" (sic). Outra participante, que nega a contribuição da OP para si, reconhece que, com a orientação, alguns colegas seus "acabavam vendo que não queriam mesmo o curso" (sic).

Diversas outras significações foram dadas ao processo vivenciado no curso: OP como ferramenta útil para uma das participantes, que até hoje, não tem segurança em relação à escolha que fez. Ainda não faz estágio e acredita que a OP poderia tê-la orientado para conseguir o imprescindível estágio, para ela um dos determinantes de seu futuro. A OP, para atender a suas necessidades, seria aquela que oferecesse orientações a respeito de como se comportar em uma entrevista de seleção de estágio, contribuísse para a formação de uma boa base e confiança e, por fim, ensinasse a fazer um currículo certo para apresentar na empresa.

Outra significação é atribuída à $O P$ como espaço para o acolhimento afetivo-emocional do aluno. Para dois dos participantes, a vivência acadêmica, com dificuldades no acompanhamento das disciplinas, gera dúvidas sobre a escolha realizada e uma sensação de solidão na vida acadêmica. Eles se percebem sozinhos, com suas dificuldades, cheios de dúvidas e desestimulados. Nessas condições, um deles ressalta a falta de um espaço de acolhimento para o enfrentamento dos desafios, e sugere que a OP na universidade representaria um espaço de acolhimento e poderia oferecer o tão necessário apoio psicológico.

Por fim, depreende-se um núcleo de significação da OP na universidade, no início/término do curso, como um espaço de orientação e preparo para a vida, pois ajudaria o aluno a lidar com a "sementinha da dúvida" (Sic). Em muitas expressões foi apontada a exigência dos professores e a complexidade dos conteúdos acadêmicos, em comparação ao Ensino Médio. De bons alu- nos, alguns passam a vivenciar reprovações ou dificuldades, gerando dúvidas sobre ter mesmo o domínio do conteúdo escolar. Esta vivência, por vezes, pode contribuir para que o universitário evoque algo em si próprio, como explicação para o baixo desempenho, de provavelmente ter "errado" no momento da escolha. Uma dos participantes sugere que a OP poderia mostrar as barreiras a enfrentar no mercado de trabalho. Outra participante, ao justificar sua ideia de que a OP no Ensino Superior apoia o aluno no percurso universitário, chama a atenção para a imagem do estudante ingressante, como quem cai de paraquedas em um mundo bem diferente daquele em que vivia. Nesse mundo, o sujeito experimenta dificuldades acadêmicas, duvida de seu domínio acerca do conteúdo escolar, sofre reprovações nas disciplinas e fica solitário em suas decisões. Para ela, a dúvida está sempre presente na trajetória do universitário, seja na chegada ao curso, seja no término de sua temporada nesse mundo diferente. Até mesmo no término do curso a dúvida pode surgir, e o aluno passa por nova situação de escolha, ao precisar definir a direção que vai tomar.

Como fruto da articulação dos achados desta pesquisa, sugere-se a importância do espaço da OP na universidade, pelo fato de, no conjunto de significações produzidas pelos participantes, terem sido recorrentes as referências à vivência em OP como contributiva e como atividade essencial no atendimento ao aluno.

\section{Considerações Finais}

Ao finalizar, resgata-se o objetivo desta pesquisa, a saber, apreender sentidos produzidos por universitários a partir da vivência no Programa de Orientação Profissional, previsto em disciplina obrigatória em uma universidade pública. A apreensão foi realizada por meio da análise dos núcleos de significação, unidade dialética que movimenta singularmente as categorias de significado e sentido, tomando-se como elemento-chave o conjunto de significações produzidas pelos participantes sobre a realidade vivida.

Por meio da análise procurou-se articular as expressões dos participantes com os elementos histórico-sociais, afetos e sentimentos, percepção de si próprio e da realidade circundante, motivos e necessidades determinantes da escolha, perspectivas de futuro e, 
especialmente, as considerações sobre o processo de OP vivenciado. A fundamentação teórica na abordagem sócio-histórica possibilitou compreender cada participante como sujeito concreto e ativo, em sua dialética constitutiva, como um ser sempre capaz de produzir novos sentidos sobre as múltiplas produções possíveis na realidade em que se move.

A consideração das particularidades do contexto social, educacional e econômico de cada um favoreceu a elaboração de núcleos de significação comprometidos com a realidade dos sujeitos e expressivos da constituição de sua subjetividade.

O movimento da pesquisa mostrou um esforço de não fragmentação da complexa subjetividade de cada participante, além de apontar que a subjetividade não é tão somente individual, mas social. Ao se justificarem e se posicionarem em relação às suas impressões e expectativas, bem como ao expressarem suas intenções e finalidades, os sujeitos da pesquisa consolidam expressões sobre a forma de satisfação de suas necessidades e produzem sentidos que têm correspondência com as circunstâncias sociais.

Foi possível apreender núcleos de significação, com variados sentidos das vivências universitárias, de suas realizações e frustrações, de explicitação da visão de si próprios, de suas produções, gostos e desgostos pelas condições enfrentadas na vivência da formação universitária, das condições que julgam necessárias para que se dê como bem sucedido seu desenvolvimento na formação profissional e seu ingresso no mundo do trabalho. Também foram explicitadas concepções sobre o trabalho, a forma de satisfação ou não na condução da vida profissional, e as expectativas relacionadas à vida pessoal/profissional.

Os variados sentidos produzidos pelos participantes e apreendidos pelo processo de análise sugerem o investimento nesse tipo de proposta de Orientação Profissional ao aluno universitário, além de favorecerem a concepção do espaço de OP na universidade como um espaço de promoção da saúde.

A despeito de se considerarem os resultados desta pesquisa como restritos a um grupo particular de universitários, os dados permitem argumentar a favor da OP no Ensino Superior, como intervenção voltada para o desenvolvimento de melhores condições de apropriação da realidade vivida pelos universitários.
Enfim, como um espaço contributivo em variados aspectos, ampliando o campo de atendimento ao aluno da graduação e oferecendo a ele um suporte específico para os projetos acadêmicos e profissionais e, também, para as tomadas de decisão ao longo do percurso acadêmico.

\section{Referências}

Aguiar, W. M. J., \& Ozella, S. (2006). Núcleos de Significação como instrumento para apreensão da constituição dos sentidos. Revista Psicologia Ciência e Profissão, 26 (2), 222-245.

Aguiar, W. M. J., Bock, A. M., \& Ozella, S. (2009). A orientação profissional com adolescentes: um exemplo de prática na abordagem sócio-histórica. In A. M. B. Bock, M. G. Gonçalves \& O. Furtado (Orgs.), Psicologia sócio-histórica: uma perspectiva crítica em psicologia. São Paulo: Cortez.

Aguiar, W. M. J, Liebesny, B., Marchesan, E. C., \& Sanchez, S. G. (2009). Reflexões sobre sentido e significado. In A. M. B. Bock \& M. G. Gonçalves (Orgs.), A dimensão subjetiva da realidade: uma leitura sócio-histórica (pp.54-72). São Paulo: Cortez.

Alfredo, R. A. (2006). Aproximações explicativas a partir da análise de sentidos e significados constituídos em espaços/ momentos/situações de escolha na escola. Dissertação de mestrado não-publicada, Programa de Pós-Graduação em Psicologia da Educação, Pontifícia Universidade Católica de São Paulo.

Bohoslavsky, R. (1977). Orientação vocacional: a estratégia clínica. São Paulo: Martins Fontes.

Calejon, L. M. C. (1995). A orientação vocacional na universidade. In A. M. B. Bock, C. M. M. Amaral, F. F. Silva, I. B. C. Silva, L. M. C. Calejon, L. Q. Andrade, et al. (Orgs.), A escolha profissional em questão (pp.177-185). São Paulo: Casa do Psicólogo.

Calejon, L. M. C. (1996). Manejo de crises e dificuldades adaptativas em universitários. Tese de doutorado não-publicada, Instituto de Psicologia Escolar e Desenvolvimento Humano, Universidade de São Paulo.

Cunha, M. I. (1997). Conta-me agora!: as narrativas como alternativas pedagógicas na pesquisa e no ensino. Revista da Faculdade de Educação, 23 (1-2), 226-237.

Dias, M. S. L. (2009). Sentidos do trabalho e sua relação com o projeto de vida de universitários. Tese de doutorado não-publicada, Programa de Pós-Graduação em Psicologia, Universidade Federal de Santa Catarina, Florianópolis.

Dias, M. S. L., \& Soares, D. (2009). Planejamento de carreira: uma orientação para estudantes universitários. São Paulo: Vetor.

González Rey, F. (2004). Osocial na psicologia e a psicologia no social. Petrópolis: Vozes.

González Rey, F. (2005). Pesquisa qualitativa e subjetividade: os processos de construção da informação. São Paulo: Thomson Pioneira. 
González Rey, F. (2007). As categorias de sentido, sentido pessoal e sentido subjetivo: sua evolução e diferenciação na teoria histórico-cultural. Psicologia da Educação, 24, 155-179.

Marques, F. M. (2007). Os sentidos que os estudantes do primeiro ano do curso de Administração de Empresas da PUC-SP atribuem ao seu projeto de futuro profissional. Dissertação de mestrado não-publicada, Programa de Pós-Graduação em Psicologia da Educação, Pontifícia Universidade Católica de São Paulo.

Moura, C. B., Sampaio, A. C. P., Menezes, M. V., \& Rodrigues, L. D. (2003). Uso de relatos escritos como instrumento de avaliação e intervenção em orientação profissional . Revista Estudos de Psicologia, 20 (3), 83-98.

Moura, C. B., \& Silveira, J. M. (2002). Orientação profissional sob o enfoque da análise do comportamento: avaliação de uma experiência. Revista Estudos de Psicologia, 19 (1), 5-14.

Novaes, C. F. (2003). As determinações sociais no problema da escolha profissional: contradições e angústias nas opções dos jovens das classes sociais de alta renda. Tese de doutorado não-publicada, Programa de Pós-Graduação em Psicologia Social, Pontifícia Universidade Católica de São Paulo.
Portilho, E. M. L. (1995). A psicopedagogia na universidade: possibilidades de reflexão e atuação-proposta de institucionalização. Dissertação de mestrado não-publicada, Programa de Pós-Graduação em Educação, Pontifícia Universidade Católica do Paraná.

Telerman, R. (2004). Projetando o futuro: a "questão feminina" dos 18 aos 21. Tese de doutorado não-publicada, Programa de Pós-Graduação em Ciências Sociais, Pontifícia Universidade Católica de São Paulo.

Valore, L. A. (2005). Subjetividade no discurso de recém- graduados da UFPR: uma análise institucional. Tese de doutorado não-publicada, Programa de Pós-Graduação em Psicologia Escolar e do Desenvolvimento Humano, Universidade de São Paulo.

Vigotski, L. S. (1998). A formação social da mente (6a ed.). São Paulo: Martins Fontes.

Vigotski, L. S. (2001). A construção do pensamento e da linguagem. São Paulo: Martins Fontes.

Zago, N. (2006). Do acesso à permanência no ensino superior: percursos de estudantes universitários de camadas populares. Revista Brasileira de Educação, 11 (32), 226-237.

Recebido em: 2/12/2010

Aprovado em: 2/9/2011 


\section{ANEXO 1}

\section{QUESTIONÁRIO}

Aqui, você encontrará perguntas relativas a algumas características pessoais, à sua formação educacional, à sua experiência profissional e à sua participação no Programa de Orientação Profissional da UFF.

Oportunamente, reiteramos nossos agradecimentos por sua participação.

Procure responder a todas as questões.

1 DADOS PESSOAIS E FAMILIARES

1.1 Nome: Sexo

1.2 Data de nasc::

Cidade: Est::

1.3 Estado civil: ( ) solteiro ( ) casado

( ) separado

( ) outro

1.4 Endereço: Rua (Av):

Bairro:

Cidade: Cel.

Tel.

E-mail

1.5 Com quem reside:

1.6 É arrimo de família, isto é, é do seu trabalho que provém a renda principal da família? Sim ( ) Não( )

1.7 Renda familiar:

( ) Até 3 salários-mínimos.

( ) De 3 a 10 salários-mínimos.

( ) De 10 a 20 salários-mínimos.

( ) Mais de 20 salários-mínimos.

1.8 Nível de escolaridade dos pais:

Ensino fundamental incompleto

Ensino fundamental completo

Ensino Médio incompleto

Ensino Médio completo

Ensino superior incompleto

Ensino superior completo

Pós-graduação

$\begin{array}{cc}\text { PAI } & \text { MÃE } \\ (\text { ) } & (\text { ) } \\ (\text { ) } & (\text { ) } \\ (\text { ) } & (~ \\ (\text { ) } & (\text { ) } \\ (\text { ) } & (\text { ) } \\ (\text { ) } & (\text { ) } \\ (\text { ) } & (\text { ) }\end{array}$

1.9 Idade e profissão dos pais:

$\begin{array}{ll}\text { PAI__ anos; } & \text { Profissão: } \\ \text { MÃE___ anos; } & \text { Profissão: }\end{array}$

\section{SUA FORMAÇÃO ACADÊMICA}

No Ensino Fundamental - Ano de conclusão

1. Todo em escola pública ( )

2. Todo em escola particular ( )

3. Maior parte em escola pública ( )

4. Maior parte em escola particular ( )

No Ensino Médio - Ano de conclusão ( )

1. Todo em escola pública ( )

2. Todo em escola particular ( )

3. Maior parte em escola pública ( )

4. Maior parte em escola particular ( )

No Ensino Superior, até o momento, você cursou:

( ) Sem cancelamento de disciplinas.

( ) Com alguns cancelamento de disciplinas.

( ) Sem algumas "VS" em disciplinas.

( ) Com algumas "VS" em disciplinas.

( ) Sem trancamento de semestre.

( ) Com trancamento de semestre.

Ano de ingresso:

Ano de conclusão:

Est.:

-


2.1 O que o motivou a fazer seu curso superior?

( ) Contato com pessoas que já faziam esse curso.

( ) Destaque da profissão no Mercado de Trabalho.

( ) Afinidade com o curso desde a formação do Ensino Médio.

( ) Adequação às habilidades pessoais.

( ) Prestígio social da profissão.

( ) Escolha resultante da orientação profissional.

( ) Influência da família.

( ) Tinha informação prévia à escolha sobre a área.

( ) OUTRO:

2.2 Está fazendo ou já fez outros cursos? Sim ( ) Não ( )

Quais?

\section{EXPERIÊNCIA PROFISSIONAL}

3.1 Você exerce alguma ocupação, atualmente? Dê informações sobre o seu trabalho. Sim ( ) Não ( )

3.1.1 Onde trabalha? Escreva um pouco sobre aspectos principais de seu trabalho, como é, o que faz etc.

3.1.2. Há quanto tempo trabalha neste local (empresa)?

( ) menos de 1 ano ( ) de 1 ano a 3 anos ( ) mais de 3 anos

3.1.3 Qual o cargo que ocupa?

3.1.4 Qual é a função que desempenha?

3.1.5 Horário de trabalho: ( ) integral ( ) parcial diurno ( ) parcial noturno

3.1.6 Você se julga é bem remunerado? Sim ( ) Não ( )

3.1.7 Sente-se satisfeito com as atividades que desenvolve em seu trabalho?

$\operatorname{Sim}($ ) Não( )

3.1.8 Quais suas aspirações profissionais atualmente?

3.2 Qual(ais) sua(s) experiência(s) profissional(ais) anterior(es)? Qual foi aquela com a qual mais se identificou? Você poderia dizer por quê?

\section{PARTICIPAÇÃO NO PROGRAMA DE ORIENTAÇÃO PROFISSIONAL}

4.1 Quando você participou do trabalho no campo da orientação profissional (OP), oferecida na disciplina Tutoria II (para alguns alunos, também oferecido no Serviço de Psicologia do DAC/UFF), vivenciava algum tipo de dificuldade com relação ao desempenho acadêmico ou quanto à identificação com o curso escolhido?
( ) Sim, de desempenho acadêmico.
( ) Sim, de identificação com o curso.
( ) Sim, ambas dificuldades.
( ) Não, nenhuma dificuldade.

4.2 Que tipos de dificuldades você julgava como sendo as de maior importância para serem superadas, para que não prejudicassem sua formação acadêmica?

( ) O curso não vinha atendendo às minhas expectativas.

( ) Outros apontavam minhas dificuldades de aprendizagem.

( ) Tinha dificuldades no acompanhamento das disciplinas do curso universitário.

( ) Falta de adequação do curso aos interesses pessoais.

406 ( ) Outro. Qual? 
4.3 Você considera que sua participação no programa POVP teve algum tipo de implicação na formação acadêmica?

( ) $\operatorname{sim}($ ) Não

4.3.1 Se sim. Por quê?

( ) Contribuiu para o aumento do empenho no curso.

( ) Colaborou com um melhor desempenho em determinadas disciplinas.

( ) Algumas disciplinas do curso universitário passaram a ter um significado diferente.

( ) Ajudou na integração da aprendizagem acadêmica ao bem-estar do dia-a-dia.

( ) Outro

Qual?

Por favor, detalhe aspectos específicos sobre as alternativas que assinalou acima:

4.3.2 Se sim, mas de modo parcial, detalhe quais aspectos o programa implicou.

4.3.3 Se não, especifique por que foi insuficiente:

4.4 Hoje, você considera que o serviço de orientação profissional contribuiu nas decisões acadêmicas e profissionais? ( ) Sim （ ) Não

4.4.1 Se sim, em quais:

( ) Proporcionou reflexão sobre possibilidades e perspectivas profissionais.

( ) Possibilitou retomar o que já havia vivenciado no percurso acadêmico.

( ) Favoreceu a possibilidade de pensar sobre a escolha do curso e sobre as dificuldades vivenciadas em relação à formação profissional.

( ) Fez adquirir meios contributivos para a superação de dificuldades.

( ) Proporcionou maior conscientização quanto ao investimento na construção da profissionalização a partir do curso universitário;

( ) Levou à compreensão das decisões a serem tomadas e possibilitaram a elaboração de projetos futuros.

( ) Auxiliou na confirmação da escolha profissional já realizada.

( ) Outro. Qual?

Por favor, escreva em detalhes de que forma as alternativas assinaladas foram contempladas em sua carreira acadêmica:

$+2$

\section{FECHAMENTO}

Deseja fazer algum comentário final?

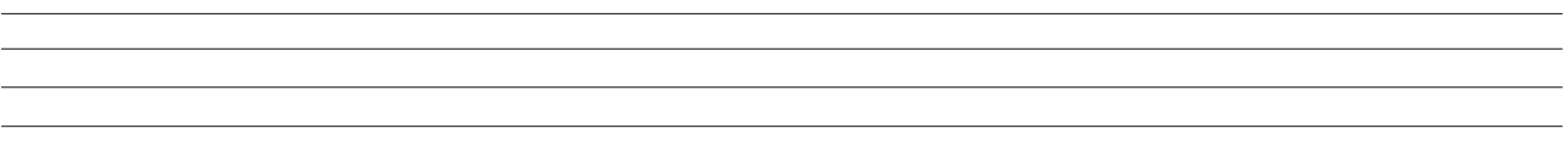

Obrigada. 
ANEXO 2

INSTRUMENTO - COMPLETAMENTO DE FRASES

Você está recebendo uma série de frases a serem completadas. Para elaboração desse conjunto de frases foram selecionados temas relacionados à sua vida e à sua vivência e produção acadêmica, na condição de aluno da UFF, bem como, simultaneamente, encontrará temas pertinentes a esta pesquisa. As frases, no total de 40 abordam como vê a si próprio e aos outros; fazem referência a respeito de como pensa e age com relação a determinadas situações, e referentes a determinados assuntos; falam sobre trajetória pessoal educacional; abordam a concepção de universidade, curso, aluno, projeto de vida, sociedade, profissão, trabalho etc.

Solicitamos que você leia cada uma delas e procure completá-las da forma mais espontânea possível, isto é, com a primeira ideia que lhe vier à mente.

1. Eu gosto...

2. Minha preocupação...

3. Eu me considero uma pessoa...

4. O mais importante na vida é...

5. Acredito que ...

6. Minha dificuldade...

7. Sobre Orientação Profissional...

8. Na minha vida escolar...

9. Penso que ficarei melhor...

10. Minha profissão...

11. O futuro...

12. Sobre a escolha penso que ...

13. Para um homem...

14. Como aluno...

15. Minha família...

16. Um bom emprego...

17. Sobre estudo, penso que...

18. Sempre que tenho oportunidade, procuro...

19. Meus amigos...

20. O trabalho...

21. Quando tenho dúvidas...

22. Uma profissão...

23. Para uma mulher...

24. Às vezes, na universidade...

25. Exige de mim esforço...

26. Os professores acham que eu...

27. Acho que posso...

28. Sobre o trabalho penso que...

29. Meu dia a dia...

그. 30. Minha maior necessidade...

궁 31.0 curso universitário...

32. Não posso...

in 33. Eu me chateio...

34. Penso que meus estudos...

35. Na universidade...

공 36. Nesta sociedade..

37. Minha formação profissional...

38. Para me realizar preciso...

408 39. Se eu pudesse... 


\section{ANEXO 3}

ORGANIZAÇÃO DOS NÚCLEOS DE SIGNIFICAÇÃO A PARTIR DAS FALAS E EXPRESSÕES DOS

PARTICIPANTES - CURSO QUÍMICA E QUÍMICA INDUSTRIAL - PERIODO 2003-2008, UNIVERSIDADE FEDERAL FLUMINENSE. NITERÓI (RJ)

\begin{tabular}{lll}
\hline Núcleos de Significação & Indicadores & Pré-Indicadores \\
\hline Não pode desistir & - "Correr atrás" para superar & - "Trabalhar e não conseguir \\
de nada! & dificuldades & estudar" \\
Tem que correr atrás! & - Não desistir de nada, dar conta de & "Sem condição financeira para \\
Tudo dá certo, se tiver & tudo & manter as despesas da \\
nosso empenho! & - Esforço próprio para superar & faculdade" \\
& dificuldades & - "Não posso desistir de nada" \\
& - Não perder oportunidades & - "Me chateio quando não dou \\
& - Não desistir nunca & conta de tudo" \\
& & - "Não posso desistir nunca" \\
& & - "Ter que correr atrás ... no fim \\
& tudo vai dar certo se nos em- \\
& penhamos para isso"
\end{tabular}

Expressões subjetivas retiradas dos relatos orais e das frases incompletas

Conteúdo temático 1 - Elementos

histórico-sociais:

"... Tive uma filha: fiquei sem tempo pra estudar e sem saber como manter as despesas da faculdade... "(Lia)

"... No início do meu curso... fazia viagem de duas horas para ir às aulas... não tinha condição financeira... fui morar de favor... acabava me atrapalhando toda... sem tempo para o meu estudo" (Maria)

Conteúdo temático 2 - O que pensa sobre si mesmo:

"... Não posso... desistir de nada.... Eu me chateio... quando não "dou conta" de tudo que tenho para fazer" (Lia)

"Não posso... desistir nunca" (Maria)

Conteúdo temático 3 - Afetos e sentimentos

"... ter que correr atrás pra aprender... Acredito que... no fim tudo vai dar certo se nos empenhamos para isso" (Lia)

Universitário:

- Dificuldades dos universitários

- "Não conseguia estudar muito, Conteúdo temático 1 - Elementos responsável pela sua vida vistas como individuais e pessoais pessoal, acadêmica e profissional - Falta de tempo para estudar: de-
sânimo e vontade de parar

- Universidade fonte de stress, de desequilíbrio, de insegurança

- Esforço e dedicação pessoal para superar dificuldades

- Na universidade tudo depende mais do aluno, tem que ser persistente

- Estudo, conhecimento e profissão: vida, sucesso e ascensão comecei a pensar em parar universidade"

- "Sempre me sinto muito sozinha com minhas dificuldades"

- "Acho que posso estudar mais"

- "Na escola eu gostava de explicar a matéria e tirar as dúvidas dos amigos"

- "Desde o início os resultados nas disciplinas me deixavam insegura, quase entrei em colapso"

- "Pensei, eu não levo jeito pra isso mesmo, desmotivada com o curso, em desequilíbrio"

- "Apenas sabia que queria fazer faculdade, estudo é muito importante para definir minha personalidade"

- "A filosofia de vida é buscar conhecimento, o curso universitário é um limiar na vida de qualquer pessoa"
"... Não tinha tempo para fazer todas as disciplinas... não conseguia estudar muito.. comecei a pensar em parar a universidade" (Laura)

"... dificuldades no curso ... sempre me sinto muito sozinha com as minhas dificuldades" (Ilana)

Conteúdo temático 2-O que pensa sobres mesmo:

"... Acho que posso... estudar mais" (Laura)

"Na escola [Ensino Médio] eu costumava tirar as dúvidas dos amigos, gostava de explicar a matéria" (Clara)

Conteúdo temático 3 - Afetos e sentimentos

"... Desde o início, os resultados nas disciplinas me deixavam insegura ... quase entre em colapso". Pensava: "Eu não levo jeito pra isso, mesmo! Me sentia em desequilíbrio desmotivada com o curso" (llana)

Conteúdo temático 4 - Elementos constituintes do direcionamento da vida

"... Terminando o ensino médio, apenas sabia que queria fazer faculdade"... "estudo é muito importante, ajuda a definir minha personalidade" (Laura) 


\section{ANEXO 3}

ORGANIZAÇÃO DOS NÚCLEOS DE SIGNIFICAÇÃO A PARTIR DAS FALAS E EXPRESSÕES DOS

PARTICIPANTES - CURSO QUÍMICA E QUÍMICA INDUSTRIAL - PERIODO 2003-2008, UNIVERSIDADE FEDERAL FLUMINENSE. NITERÓI (RJ)

Continuação

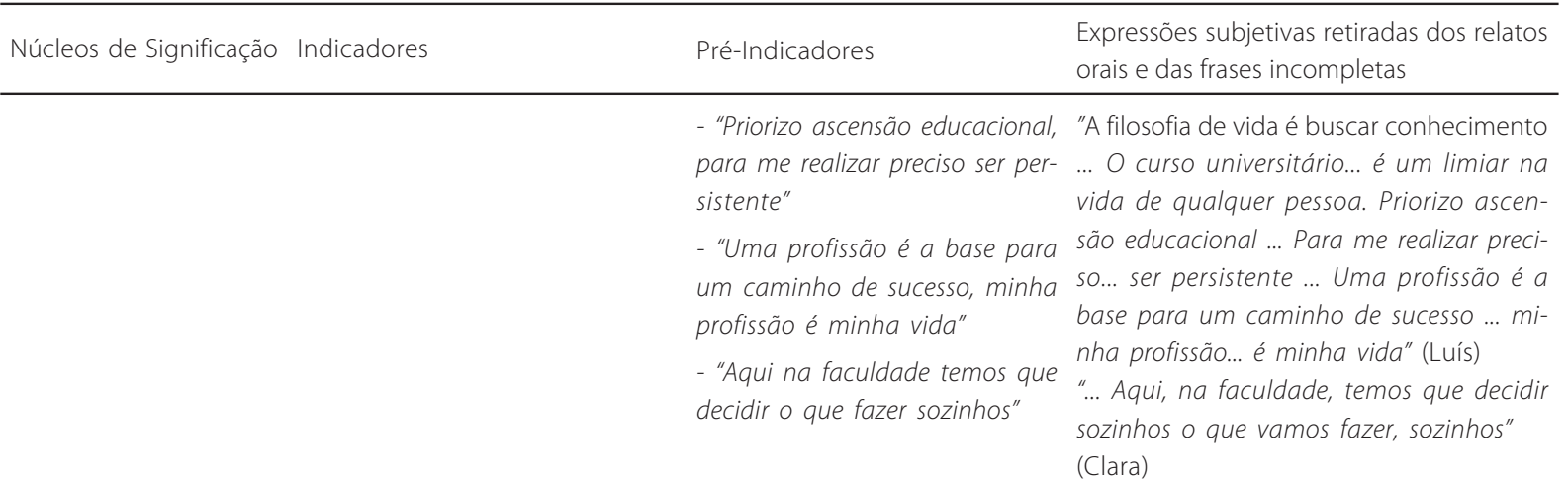

Condições para a apro- - "Na identificação com o curso, a - "A cada momento me certifica- Conteúdo temático 5 - Apropriação e priação do conheci- base para aprender bastante" va da identificação com a Quími- objetivação do conhecimento

mento determinante do - "Apropriação do conhecimento ca, tenho aprendido bastante" "... Química, uma área que a cada momendesempenho acadêmi- determinante da escolha" - "Prá que estou aprendendo to eu me certificava da identificação com co e da confirmação da _ "Apropriação do conhecimento: isso? Será que vai ter ligação ela, ... tenho aprendido bastante" (Laura) escolha profissional relação com a prática" com a prática?" ".. Durante o curso, fiquei me perguntan- "Aluno esforçado: base para ser - "Preciso correr atrás para con- do: Pra que estou aprendendo isso? Será bem sucedido no curso e na pro- seguir ser uma profissional bem que esse conhecimento vai me servir? Será fissão" sucedida"

- "Fazendo o curso difícil não conseguia assimilar a vida universitária nem saber se ainda quer fazer a formação"

- "A cada superação acabava confirmando se queria o curso e a profissão" que vai ter alguma ligação com a minha prática? ... "Preciso correr atrás, para conseguir ser uma profissional bem sucedida" (Júlia)

"... tumulto acontecendo na minha vida ... fazendo o curso difícil como o de Química, eu não conseguia assimilar a vida universitária. ... nem sabia se realmente eu queria ainda fazer Química" (Maria)

"... Tive que correr muito atrás para poder superar ... falta de base ... a cada passo, a cada superação que eu conseguia has disciplinas, eu acabava confirmando, se eu, realmente, queria esse curso e essa profissão" (Luís)

Estudo: realização pes- - "Iniciação científica e estágio: - "Trabalho é uma das melhores soal $X$ realização profis- aprendizado e satisfação" ocupações, faz me sentir viva

sional X realização social - "Conhecimento e prática: condie financeira ções de inserção no mercado de trabalho"

- "Conhecimento e prática: realização pessoal + desenvolvimento profissional = ascensão financeira"

"Trabalho como bolsista, ain-

Conteúdo temático 9 - Trabalho/profissão

"O trabalho... é uma das minhas melhores como profissional con- "... Sei que estou formada há apenas dois tratada, incluída no mercado de trabalho"

... Sel que estou formada há apenas dois de Tecnologia do CNPa, mas como bolsis- "Passei a trabalhar em labora- ta, ainda não como uma profissional contório, também faço a Iniciação tratada, incluída no mercado de trabaCientífica, tenho gostado muito Iho..." (Júlia)

do que faço, sei que é esta área "... Passei a trabalhar em um novo laboraque eu quero seguir"

tório ... também faço a Iniciação Científica - "Quando você vai procurar uma ... tenho gostado muito do que faço. ... sei vaga de trainee, é sempre pedida que é esta área que eu quero seguir" (Laura) a experiência profissional"

410 
ANEXO 3

ORGANIZAÇÃO DOS NÚCLEOS DE SIGNIFICAÇÃO A PARTIR DAS FALAS E EXPRESSÕES DOS PARTICIPANTES - CURSO QUÍMICA E QUÍMICA INDUSTRIAL - PERIOODO 2003-2008, UNIVERSIDADE FEDERAL FLUMINENSE. NITERÓI (RJ)

Continuação

Expressões subjetivas retiradas dos relatos orais e das frases incompletas

- "A entrada no mercado de tra- ".. Já estou saindo da faculdade e ainda balho é difícil, o trabalho é um nem estagiei ... Quando você vai procurar dos caminhos da ascensão social" uma vaga de trainee, é sempre pedida a - "Profissão é a base do sucesso" experiência profissional ... se você não teve - "Comecei a estagiar gosto do é eliminado no processo de seleção" (Ilana) meu trabalho"

"... Sei que, hoje em dia, a entrada no mercado de trabalho é difícil ... O trabalho é um dos caminhos da ascensão social e financeira" (Clara)

"Uma profissão é a base para um caminho de sucesso" (Luís)

"... Comecei a estagiar, há dois anos, em uma escola ... gosto do meu trabalho também da Química" (Clara)

O futuro nas mãos de - O futuro nas mãos de Deus/exis- - "Na vida universitária, tudo de- Conteúdo temático 4 - Elementos constiDeus tência de elementos orientadores pende da gente" tuintes do direcionamento da vida para a vida, advindos de lastro éti- - "O mais importante na vida é... co - religioso x concepção de ho- Deus" mem liberal

- "Concretização dos planos pessoais e de realização profissional "nas mãos de Deus"

- "Na faculdade temos que decidir o que fazer sozinhos"

"... Na vida universitária, tudo depende muito mais da gente, do que dos outros. ... O mais importante na vida é ... viver com todos os obstáculos" (Lia)

"O mais importante na vida é... Deus ... Para me realizar preciso apenas cumprir os mandamentos" ... "O futuro nas mãos de Deus" (Maria)

Projeto de futuro como - Futuro: incertezas

- "Futuro promissor a partir da Conteúdo temático 10 - Projeto de vida contradição entre a cer- - Vida profissional futura: preocu- tomada de decisão" teza e a incerteza da pação

- "Futuro depende de nós" "O futuro só depende de nós e de tudo que escolha

- "Futuro é incerto" fazemos" (Lia)

- "Futuro será realização do sonho" "... formada há dois meses ... só preciso correr atrás, para ser uma profissional bem sucedida" (Júlia)

- "Futuro só depende de nós e de tudo que fazemos"

"Tinha um sonho ... formação universitá- "Final do curso preocupação é ria". "Minha formação profissional será com a vida futura" uma grande conquista" (Luís)

"... neste final do curso gostaria de saber que barreiras eu iria enfrentar se escolher ser professora. ... Minha preocupação é com minha vida futura" (Clara)

OP: conscientização da - Conscientização da diferença en- - "Fiquei satisfeita por ter encon- Conteúdo temático 6 - Elementos da vida real situação do curso

perio

- Mudança na direção dos estudos, após participação na OP - Conscientização da necessidade de maior empenho para superar dificuldades nas disciplinas trado o curso com mais afinida-

de; passei a me dedicar mais aos "... [após a Tutoria II] fui fazer, junto, o 10 $\begin{array}{ll}\text { - sestudos" } & \text { semestre de Microimunologia ... fiquei sa- } \\ \text { - Me dificuldade para tisfeita ... ter encontrado o curso que eu iria }\end{array}$ acompanhar o curso era maior ter mais afinidade ... e assim, fazer a mudo que eu imaginava, faltava dança na minha vida ... passei a me dedibase do ensino fundamental e car mais aos estudos" (Laura) médio"

"... Na universidade ..., meu nível de dificul- "Primeiro período do curso foi dade para acompanhar o curso era muito catastrófico, curso difícil, diferen- maior do que eu imaginava ... faltava base ça do ensino médio"
... desde o ensino fundamental e médio ... tive que correr muito atrás para poder conseguir a superação nas disciplinas" (Luís) 


\section{ANEXO 3}

ORGANIZAÇÃO DOS NÚCLEOS DE SIGNIFICAÇÃO A PARTIR DAS FALAS E EXPRESSÕES DOS

PARTICIPANTES - CURSO QUÍMICA E QUÍMICA INDUSTRIAL - PERIODO 2003-2008, UNIVERSIDADE FEDERAL FLUMINENSE. NITERÓI (RJ)

\begin{tabular}{|c|c|c|c|}
\hline Núcleos de Significação & Indicadores & Pré-Indicadores & $\begin{array}{l}\text { Expressões subjetivas retiradas dos relatos } \\
\text { orais e das frases incompletas }\end{array}$ \\
\hline & \multirow[t]{2}{*}{$\begin{array}{l}\text { - Conscientização do nível de exi- } \\
\text { gência do curso }\end{array}$} & $\begin{array}{l}\text { - "Tive que correr muito atrás } \\
\text { para conseguir a superação nas } \\
\text { disciplinas" }\end{array}$ & $\begin{array}{l}\text { "... primeiro período do curso foi catastrófi- } \\
\text { co ... curso difícil ... não conseguia assimilar } \\
\text { a vida universitária ... diferença grande do } \\
\text { ensino médio para a universidade" (Maria) }\end{array}$ \\
\hline & & $\begin{array}{l}\text { - "Participei do trabalho de OP } \\
\text { até aquela hora, não tinha caí- } \\
\text { do a minha ficha, em relação a } \\
\text { minha real situação no curso" }\end{array}$ & $\begin{array}{l}\text { Conteúdo temático } 8 \text { - Orientação profissional } \\
\text { "... Participei do trabalho de OP da Tutoria II } \\
\text {... depois de ter feito ... continuei, cada vez } \\
\text { mais, com a ideia de mudar a minha dire- } \\
\text { ção nos estudos ... minha carreira profis- } \\
\text { sional ... Até aquela hora, não tinha caído } \\
\text { a minha ficha, em relação a minha real } \\
\text { situação no curso de Química. Foi a partir } \\
\text { daí ... que pude saber o que, realmente, } \\
\text { queria fazer" (Laura) }\end{array}$ \\
\hline
\end{tabular}

OP revela tardiamente - OP confirma a escolha aquilo que se sabia
- OP não interessa para quem tem "certeza" da escolha"

- OP confirma a incompatibilidade com o curso
- "Eu já sabia que eu queria fazer" Conteúdo temático 8 - Orientação profissional

- "Orientação só serviu para me "... Eu já sabia que eu queria fazer Química, firmar"

o processo de orientação só serviu pra me - "Orientação não interessou, firmar mesmo. ... pra ver ... que a Química não tinha dúvidas" era realmente o que eu queria fazer" (Lia) - "No caso de outras pessoas, acabavam vendo que não que riam mesmo o curso"

"Tutoria II, ... não interessou ... não tinha dúvidas em relação à escolha" "... no caso de outras pessoas ... tinha aluno que não estava se dando bem com as matérias... pensava em desistir da faculdade. Com a orientação ... acabavam vendo que não queriam mesmo o curso" (Júlia)

OP como espaço para - Dúvida e questionamentos sobre - "Agora, no último período, ain- Conteúdo temático 7 - Escolhas repensar escolha profis- a escolha do curso e a continuida- da me vejo sem certeza se a misional de ou mudança nha escolha pelo curso foi acerOP como processo pro- - OP no início: bom para a dúvida tada" veitoso da escolha e para ter visão melho- - "Fiz a escolha do curso, mas não OP como ferramenta útil rada do curso tinha noção sobre a área de traOP na universidade: iní- - OP no término do curso: nova balho da Química" cio e término do curso situação de escolha profissional OP como espaço para - OP no final: preparo e confiança acolhimento afetivo- para início da vida profissional -emocional do aluno

- OP como espaço para acolhimento afetivo-emocional do aluno

- " no médio

- "Uma professora me deu a ideia para fazer Química porque eu tinha facilidade na matéria. No primeiro semestre me perguntava: É esse mesmo o curso que devo fazer?"

- "No final do curso, a dúvida de novo"
"... No quinto período do curso universitá rio ... me batia 'aquela dúvida', e me perguntava: Será que é esse mesmo o meu caminho? ... agora, no último período ... ainda me vejo sem certeza ... se a minha escolha pelo curso, foi uma escolha acertada" (Ilana)

"Fiz a escolha deste curso, mas, não tinha uma boa noção sobre a área de trabalho da Química" (Luís)

"... Eu fiz a escolha curso de Química influenciada por uma professora do ensino médio ... me fez pensar que gostava de Química" (Maria)

"... A minha professora chegou e me deu a ideia para fazer Química, porque eu tinha muita facilidade na matéria. ... no primeiro semestre me perguntava: Será que é esse o curso que devo fazer? Na fase final do curso, a dúvida bate de novo" (Clara)

412 


\section{ANEXO 3}

ORGANIZAÇÃO DOS NÚCLEOS DE SIGNIFICAÇÃO A PARTIR DAS FALAS E EXPRESSÕES DOS

PARTICIPANTES - CURSO QUÍMICA E QUÍMICA INDUSTRIAL - PERIOODO 2003-2008, UNIVERSIDADE FEDERAL FLUMINENSE. NITERÓI (RJ)

Conclusão

\begin{tabular}{|c|c|c|c|}
\hline Núcleos de Significação & Indicadores & Pré-Indicadores & $\begin{array}{l}\text { Expressões subjetivas retiradas dos relatos } \\
\text { orais e das frases incompletas }\end{array}$ \\
\hline \multirow[t]{4}{*}{$\begin{array}{l}\text { OP na universidade: es- } \\
\text { paço de orientação e } \\
\text { preparo para vida pro- } \\
\text { fissional }\end{array}$} & \multirow[t]{4}{*}{$\begin{array}{l}\text { - OP: trabalho com "sementinha } \\
\text { da dúvida" }\end{array}$} & $\begin{array}{l}\text { - "Orientação no início do curso } \\
\text { é bom para dúvida da escolha, } \\
\text { ter visão melhorada do curso; } \\
\text { no final do curso podia ajudar } \\
\text { para dar base e confiança para } \\
\text { construção de currículo e pro- } \\
\text { cura de estágio" }\end{array}$ & $\begin{array}{l}\text { Conteúdo temático } 8 \text { - Orientação profissional } \\
\text { "... Orientação, no início do curso, é bom } \\
\text { para dúvida da escolha ... ter uma visão } \\
\text { melhorada do seu curso ... no final do cur- } \\
\text { so podia ajudar ... dar uma boa base e } \\
\text { confiança para o aluno fazer seu currículo } \\
\text { e procurar estágio. Sobre Orientação Pro- } \\
\text { fissional... ferramenta útil" (Ilana) }\end{array}$ \\
\hline & & - "OP: ferramenta útil" & \multirow{2}{*}{$\begin{array}{l}\text { "... um trabalho importante ... além de tra- } \\
\text { balhar a escolha profissional ... passa pro } \\
\text { aluno que ... está sendo acolhido na Uni- } \\
\text { versidade. ... deveria ter uma sequência no } \\
\text { decorrer de todo o curso de graduação" } \\
\text { (Luís) }\end{array}$} \\
\hline & & $\begin{array}{l}\text { - "[OP] um trabalho importante, } \\
\text { trabalha a escolha profissional } \\
\text { e faz o acolhimento do aluno" }\end{array}$ & \\
\hline & & $\begin{array}{l}\text { - "Na Tutoria foram mostrando } \\
\text { caminhos que ajudam a lidar } \\
\text { com a "sementinha da dúvida" }\end{array}$ & $\begin{array}{l}\text { "Na Tutoria, vocês foram mostrando ca- } \\
\text { minhos que ajudam a lidar com essa } \\
\text { sementezinha da dúvida, uma dúvida que } \\
\text { eu acho que fica sempre ... dúvida sobre a } \\
\text { escolha da profissão" (Clara) }\end{array}$ \\
\hline
\end{tabular}

OP: Orientação Profissional.

413 
